\title{
Prevalence and Prognostic Significance of HPV in Laryngeal Squamous Cell Carcinoma in Northeast China
}

\author{
Fangjia Tong Jingshu Geng ${ }^{\mathrm{c}}$ Bingqing Yan ${ }^{\mathrm{a}, \mathrm{b}}$ Huihuang Lou ${ }^{\mathrm{a}, \mathrm{b}}$ \\ Xiaohang Chen ${ }^{a, b} \quad C^{2}$ Chwei Duan ${ }^{a, b}$ Jing He ${ }^{c}$ Siwei Zhang ${ }^{a, b} \quad H u a n h u a n X^{a, b}$ \\ Huining Lid ${ }^{d}$ Dawei Yuan ${ }^{c}$ Fengmin Zhang ${ }^{a, b}$ Hongxue Meng ${ }^{c}$ Lanlan Wei ${ }^{a, b}$ \\ aDepartment of Microbiology, Harbin Medical University, Harbin, bWu Lien-Teh Institute, Harbin \\ Medical University, Harbin, 'Department of Pathology, Harbin Medical University Cancer Hospital, \\ Harbin, dDepartment of Pathology, Harbin Medical University \& Department of Pathology, the First \\ Affiliated Hospital of Heilongjiang University of Chinese Medicine, Harbin, China
}

\section{Key Words}

Human papillomavirus - Laryngeal squamous cell carcinomas • P16 • Prognosis • Overall survival

\begin{abstract}
Background/Aims: Human papillomavirus (HPV) is an etiological risk factor for a subset of head and neck squamous cell carcinomas. HPV has been proven to be a powerful prognostic biomarker for oropharyngeal cancer, but its role in the larynx has not been explored in depth. Here, we sought to evaluate the prevalence and genotype distribution of HPV in patients with laryngeal squamous cell carcinoma (LSCC) in northeast China. Methods: HPV DNA in specimens from 211 patients diagnosed with LSCC was analyzed by the polymerase chain reaction and in situ hybridization, and p16 overexpression was evaluated by immunohistochemistry. p16 expression was scored positive if strong and diffuse nuclear and cytoplasmic staining was present in $>75 \%$ of tumor cells. Results: In this study, infection with HPV and p16 expression were not absolutely consistent. Among all patients, 132 (62.6\%) were positive for HPV DNA (HPV+), while 23 (10.9\%) were inconsistent for HPV and p16. Multivariate analysis indicated that HPV, but not p16, is an independent prognostic factor for overall survival in LSCC. Overall survival was significantly improved in HPV + LSCC patients compared with the HPV-negative group (hazard ratio, 0.395; 95\% confidence interval, 0.185-0.843; $p=0.016$ ). Among the 132 HPV + patients, 28 (21.2\%) were HPV-16 single infection. Conclusion: This study indicates that HPV DNA is a more reliable surrogate marker than p16 for the prediction of survival in patients with LSCC.
\end{abstract}




\section{Cellular Physiology Cell Physiol Biochem 2018;49:206-216 \begin{tabular}{ll|l} 
and Biochemistry Published online: 22 August, 2018 & $\begin{array}{l}\text { (C) } 2018 \text { The Author(s). Published by S. Karger AG, Basel } \\
\text { www.karger.com/cpb }\end{array}$
\end{tabular} \\ Tong et al.: Prognostic Significance of HPC in Laryngeal Cancer}

\section{Introduction}

Head and neck squamous cell carcinoma (HNSCC) is the sixth most common cancer worldwide and arises in different anatomical regions, including the oral cavity, oropharynx, hypopharynx, and larynx [1]. Human papillomavirus (HPV) has been recognized as an etiological risk factor for a subset of HNSCC, especially oropharyngeal squamous cell carcinoma (OPSCC). The prevalence of HPV in OPSCC is approximately 60\% [2]. It has been well accepted that OPSCC can be divided into HPV-positive (HPV+) and HPV-negative (HPV-) tumors. HPV+ OPSCC is unique in its pathogenesis, epidemiology, and clinical features [3]. Individuals with HPV+ OPSCC have a strikingly improved prognosis compared with HPVOPSCC patients, with a $20-80 \%$ reduction in the risk of death $[4,5]$.

In HPV+ tumors, E6/E7 oncogene activity leads to p53 (TP53) and retinoblastoma 1 inactivation and $\mathrm{p} 16^{\mathrm{INK4A}}(\mathrm{p} 16)$ upregulation [6-8]. p16 is considered a reliable surrogate marker for HPV+ tumors. Previous studies have indicated that 16 upregulation can be used as a prognostic biomarker in OPSCC $[4,9]$. Laryngeal squamous cell carcinoma (LSCC) is the second most common malignancy of HNSCC with an incidence of $>151,000$ cases/year worldwide $[10,11]$. HPV-associated HNSCC has been fully evaluated in the United States, Sweden, and other countries. In Europe, the prevalence of HPV in HNSCC is $28.2 \%$, and $47 \%$ of cases with HNSCC are HPV+ in North America [12-14]. However, only a few studies have examined HPV-associated HNSCC in China [15]. Numerous studies have focused on HPV and p16 in OPSCC, while very few studies have addressed LSCC [16-18].

In this study, we analyzed the status of HPV infection and p16 expression in patients with LSCC. Tissue samples were collected in Heilongjiang Province in northeast China. We evaluated the prevalence, clinical features, and prognosis of HPV-related LSCC, and determined whether HPV or p16 could serve as surrogate markers for the prognosis of LSCC.

\section{Materials and Methods}

\section{Patients and tissue samples}

A total of 211 patients diagnosed with LSCC treated with surgery were admitted to the Third Affiliated Hospital of Harbin Medical University. All patients and their families provided written informed consent regarding this study, and ethical approval for the study was obtained from the Ethics Committee of Harbin Medical University.

Clinical information and patient outcomes were obtained from medical records. The patients were treated with radiotherapy with or without chemotherapy according to national guidelines. The curative radiotherapy fractionated regimen consisted of 60 Gy in 6 fractions per week. Information including sex, age, history of smoking and alcohol use, tumor location, tumor, node, metastasis (TNM) stage, and treatment regimen was collected for each patient. TNM stage was defined according to the American Joint Committee on Cancer staging system. Tumor differentiation was scored on an ordinal scale as well as moderate or poor differentiation according to the hierarchy of tumor cell differentiation.

Tumor specimens were collected during surgery, and one representative paraffin block was selected for each patient. Eight 5- $\mu$ m-thick paraffin sections were used for HPV polymerase chain reaction (PCR) and typing, and three 3- $\mu \mathrm{m}$-thick serial sections were used for hematoxylin and eosin staining, immunohistochemistry (IHC) of p16, and in situ hybridization (ISH) of HPV DNA. In order to avoid crosscontamination, the microtome was cleaned with a disposable tissue soaked in $70 \%$ ethanol before and after each block was sectioned. In addition, the blade was changed before a new paraffin block was sectioned. The sections were transferred to a sterile 1.5-mL Eppendorf tube with tweezers, which were then cleaned with a disposable tissue soaked in $70 \%$ ethanol. After each tenth LSCC block, 7 sections were taken from a mouse tissue block as a negative control. 


\section{Cellular Physiology Cell Physiol Biochem 2018;49:206-216 \begin{tabular}{l|l|l} 
and Biochemistry & Dublished online: 22 August, 2018 & $\begin{array}{l}\text { (c) 2018 The Author(s). Published by S. Karger AG, Basel } \\
\text { www.karger.com/cpb }\end{array}$
\end{tabular}}

\section{HPV PCR and typing}

Genomic DNA was extracted from tissue samples using a TIANamp FFPE DNA Kit (Tiangen, Beijing, China). DNA concentration was determined using a NanoDrop 2000C spectrophotometer (Thermo Scientific, Waltham, MA). Human globin DNA was amplified by PCR using $\beta$-globin primers. To increase the sensitivity of HPV detection, HPV DNA was amplified by nested PCR using MY09/11 and GP5+/6+ primers with the following sequences: MY09: 5'-CGTCCMARRGGAWACTGATC-3', MY11: 5'-GCMCAGGGWCATAAYAATGG-3'; GP5+: 5'-TTTGTTACTGTGGTAGATACTA-3', GP6+: 5'-GAAAAATAACTGTAAATCATTTC-3'. This technique can identify low copy numbers of a broad range of both low-risk and high-risk HPV. PCR amplification was performed as follows: initial denaturation at $95^{\circ} \mathrm{C}$ for $5 \mathrm{~min}$; 40 cycles of denaturation at $95^{\circ} \mathrm{C}$ for $1 \mathrm{~min}$, annealing at $55^{\circ} \mathrm{C}$ for $1 \mathrm{~min}$, and extension at $72{ }^{\circ} \mathrm{C}$ for $1 \mathrm{~min}$; and final extension at $72{ }^{\circ} \mathrm{C}$ for $4 \mathrm{~min}$. The PCR product was then used as a template for the second PCR. Cervical squamous cell carcinoma with HPV infection was used as a positive control, and $\mathrm{ddH}_{2} \mathrm{O}$ was used as a negative control. The final PCR products were separated by electrophoresis through $1.5 \%$ agarose gels. HPV DNA+ samples were characterized according to HPV genotype. HPV genotypes, including high-risk (HPV-16, -18, -13, and -58) and low-risk (HPV-11), were determined by amplicon hybridization analysis (Hybribio Biotechnology Limited Corp., Chaozhou, China).

p16IHC

IHC was performed using a monoclonal antibody against p16 INK4a (ZM-0205; ZSGB-BIO, China) according to a previously published protocol [19]. Briefly, formalin-fixed, paraffin-embedded tumor tissue specimens were deparaffinized. Heat-induced antigen retrieval was performed in Tris-EDTA (pH 9.0; Dako, Denmark) according to the manufacturer's recommendations. Subsequent sample processing was carried out using the Dako Envision-System. Cervical squamous cell carcinoma with high p16 expression was used as a positive control, and omission of the primary antibody was used as a negative control. A specimen was judged to be p16-positive (p16+) if nuclear and cytoplasmic signals were detected in $>75 \%$ of tumor cells. Representative images for p16 IHC are shown in Fig. 1A.

\section{HPV DNA ISH}

DNA ISH was performed using HPV III family 16 probes (TIB, Xiamen, China) that detect HPV-16, -18 , $-31,-33,-35,-39,-45,-51,-52,-58,-59,-68$, and -70. HPV DNA ISH was performed on $3-\mu m$-thick tissue sections. After deparaffinization and rehydration, the sections were incubated in $0.8 \%$ pepsin at $37^{\circ} \mathrm{C}$ for 5-10 min and then treated with proteinase at room temperature for $5 \mathrm{~min}$. The sections were immersed in $0.3 \% \mathrm{H}_{2} \mathrm{O}_{2}$ (in methanol) for $20 \mathrm{~min}$, denatured, and hybridized overnight at $37^{\circ} \mathrm{C}$. Hybridized probes were detected using diaminobenzidine.

\section{The Cancer Genome Atlas and Gene Expression Omnibus data}

Clinical data on $6 \mathrm{HPV}+$ and $20 \mathrm{HPV}$ - LSCC patients were downloaded from The Cancer Genome Atlas (TCGA) (https://cancergenome.nih.gov). One additional, independent dataset (GSE65858) containing HPV DNA/RNA status and survival data was obtained from the Gene Expression Omnibus (GEO) (https://www. ncbi.nlm.nih.gov/gds/), including 3 HPV+ and 45 HPV- LSCC cases. A total of 74 samples that contained clinical characteristics, survival information, and HPV status were included in this study. Due to the small number of HPV+ LSCC cases, we combined TCGA and GEO LSCC data to investigate the relationship between HPV DNA/RNA and clinical outcome.

Fig. 1. Detection of $\mathrm{p} 16$ protein and HPV DNA in LSCCs. (A) p16 protein detection by IHC and H\&E staining of LSCC tumor tissue. p16+ sample showing strong, diffuse $\mathrm{p} 16$ expression in tumor cells. (B) HPV status in LSCC detected by HPV-DNA ISH. HPV+ case showing strong, punctuate signal. Images from $10 x$ and $20 x$

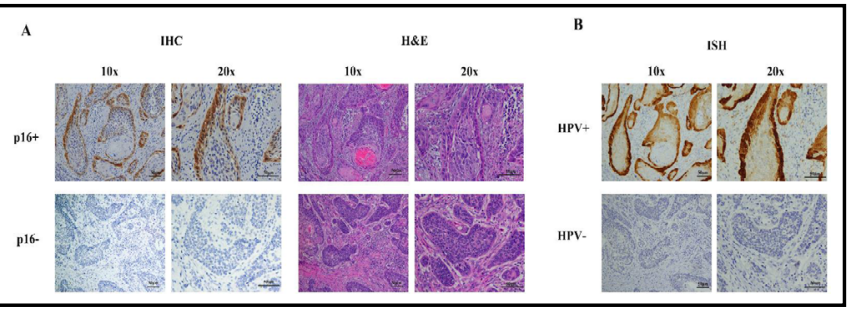
objective lens. LSCC, laryngeal squamous cell carcinoma; IHC, immunohistochemistry; ISH, in situ hybridization; HPV, human papillomavirus. 


\section{Cellular Physiology Cell Physiol Biochem 2018;49:206-216 \begin{tabular}{ll|l} 
and Biochemistry Published online: 22 August, 2018 & $\begin{array}{l}\text { (C) } 2018 \text { The Author(s). Published by S. Karger AG, Basel } \\
\text { www.karger.com/cpb }\end{array}$
\end{tabular}

\section{Statistical analysis}

Overall survival was determined from the date of diagnosis to the date of death (due to any cause), or to the end of the follow-up period (December 31, 2016). Overall survival probability was determined from a Kaplan-Meier curve, and comparisons were made using log-rank tests. The Cox regression model was used to evaluate the impact of various factors on overall survival by multivariate analysis. All statistical analyses were two-sided and performed using IBM SPSS statistics software version 16 (SPSS Inc., Chicago, IL). Differences were considered statistically significant for a $P$-value $\leq 0.05$.

\section{Results}

Characteristics of LSCC patients stratified by $p 16$ and HPV status

LSCC patient samples were tested by p16 IHC (Fig. 1A), HPV PCR, and HPV DNA ISH (Fig. 1B). p16+ signals appeared as strong and diffuse nuclear and cytoplasmic staining in tumor cells. ISH+ signals appeared strong and punctate in tumor cell nuclei. Among the 211 LSCC patients, 132 (62.6\%) were HPV+ by PCR analysis; of these, 131 were also HPV+ by ISH assay. Of the 211 patient specimens tested, 115 (54\%) were positive for p16 by IHC analysis. p16 expression was strongly associated with HPV status $(97.39 \%$ in HPV+ samples vs. $2.61 \%$ in HPVsamples, $P<0.001$ ) (Table 1 ).

The characteristics of LSCC patients are listed in Table 2 . The median age was 58 years (range 37-80). Most were males (85.8\%) with early stage disease (stage I or II) at diagnosis. On the basis of $\mathrm{p} 16$ expression or HPV status, the patients were divided into $\mathrm{p} 16+/ \mathrm{p} 16-$ and HPV+/HPV- groups. p16+ patients were significantly older than p16- patients $(88.70 \%$ vs. $77.08 \%$, respectively, $P=0.038$ ). $\mathrm{HPV}+$ patients were slightly, but not significantly, older than HPV- patients (86.36\% vs. $78.48 \%$, respectively, $P=0.194)$. p16+ patients tended to have longer smoking histories ( $>20$ years) than p16- cases $(71.30 \%$ vs. $58.33 \%$, respectively, $P=0.127$ ); this trend was less marked for HPV+ patients compared with HPV- patients (66.63\% vs $63.29 \%$, respectively, $P=0.873$ ). p16+ LSCC was more likely to present as a well differentiated lesion compared with p16- LSCC (50.43\% vs. $46.88 \%$, respectively, $P=0.002$ ), while HPV+ LSCC more frequently presented as a moderately differentiated lesion compared with HPV- LSCC (45.45\% vs. $27.85 \%$, respectively, $P=0.021) \cdot \mathrm{p} 16+$ LSCC presented more often as a glottic lesion compared with p16- LSCC (36.52\% vs. $17.71 \%$, respectively, $P=0.010$ ), and a similar trend was observed between the HPV+ and HPV- groups (33.33\% vs. 18.99\%, respectively, $P=0.080$ ).

Table 2. Demographic and clinical characteristics in LSCCs. $P$-values were calculated with chi-square test

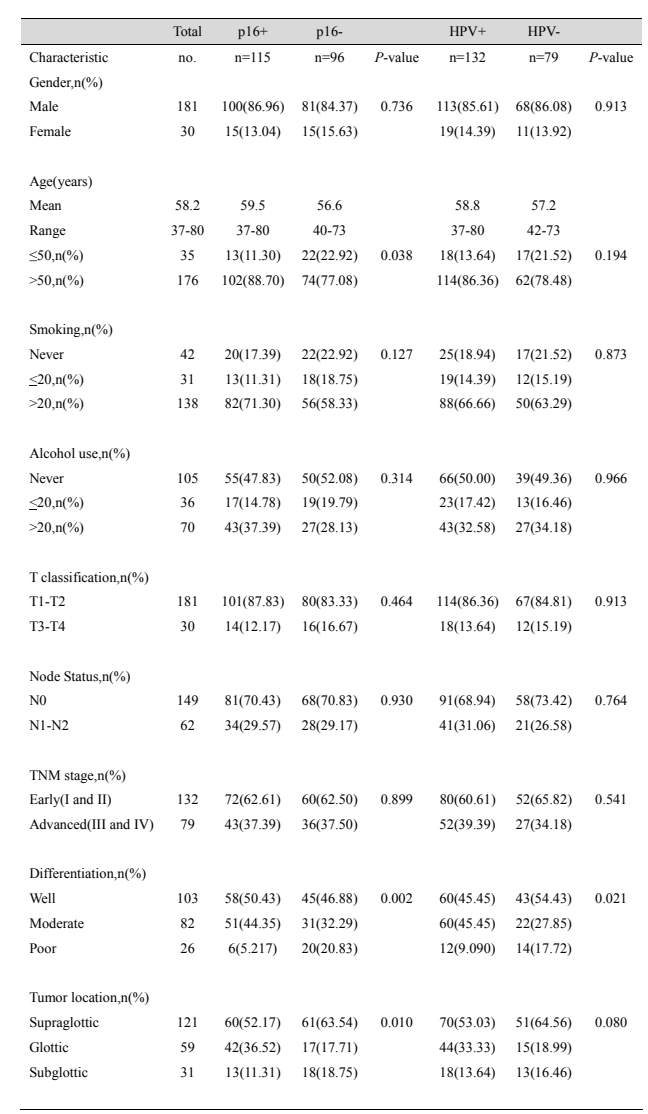

Table 1. The status of HPV and p16 expression in LSCCs. $P$-values were calculated with chi-square test

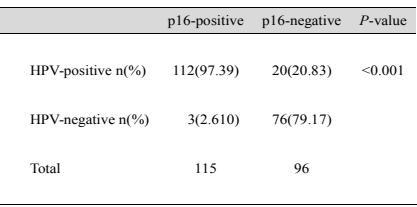


There was no significant difference between the $\mathrm{p} 16+/ \mathrm{p} 16-$ or HPV+/HPV- groups with regard to sex, alcohol use, T classification, node status, or TNM stage.

\section{Single and multiple HPV infections}

The $132 \mathrm{HPV}+$ patient samples were all positive for HPV-16. Of these, 28 samples showed multiple HPV infections. Patients with a single HPV infection tended to have longer ( $>20$ years) smoking histories $(70.20 \%$ vs. $53.57 \%$, respectively, $P=0.123$ ) and alcohol use (38.46\% vs. $10.71 \%$, respectively, $P=0.007$ ) compared with patients with multiple HPV infections. LSCC with a single HPV infection presented more frequently with lymph node metastasis $335.58 \%$ vs. $14.29 \%$, respectively, $P=0.053$ ) and advanced TNM stage (44.23\% vs. $21.43 \%$, respectively, $P=0.048$ ) compared with LSCC with multiple HPV infections (Table 3).

On the basis of tumor origin, LSCCs were subdivided into supraglottic, glottic, and subglottic types. The association between HPV genotype and tumor location was analyzed thoroughly (Table 4). HPV-16 (53.03\%) was most frequently present in supraglottic-type tumors. while HPV-18 (46.43\%) was mainly present in glottic-type tumors.

\section{Overall survival for LSCC patients}

On the basis of Kaplan-Meier curves, we examined overall survival for LSCC patients stratified according to p16, HPV, and infection status (Fig. 2). Although p16+ patients appeared to exhibit better survival compared with p16- patients, log-rank tests indicated no significant difference $(P=0.1443)$ (Fig. 2A). $\mathrm{HPV}+$ patients exhibited a significantly better overall outcome than HPV- patients $(P=0.0136)$ (Fig. 2B). Patients with a single HPV infection tended to have a better survival outcome than those with multiple HPV infections, though this difference was not statistically significant $(P=0.1190$ ) (Fig. 2C).

Multivariable logistic regression analysis was performed for overall survival to eliminate potential confounding effects for HPV, p16, and other independent factors (Table 5). The results indicated that HPV status tended to be an independent and significant prognostic factor in predicting overall survival for patients with LSCC (hazard ratio [HR], 0.395; 95\% confidence interval $[\mathrm{CI}], 0.185-0.843 ; P=0.016)$. By contrast, $\mathrm{p} 16$
Table 3. The characteristics of HPV infection in LSCCs. $P$-values were calculated with chi-square test

\begin{tabular}{|c|c|c|c|c|}
\hline \multirow[b]{3}{*}{ Characteristic } & \multicolumn{3}{|c|}{ HPV } & \multirow[b]{3}{*}{$P$-value } \\
\hline & & single infection & multiple infection & \\
\hline & no. & $\mathrm{n}=104$ & $\mathrm{n}=28$ & \\
\hline \multicolumn{5}{|l|}{ Gender,n(\%) } \\
\hline Male & 113 & $90(86.54)$ & $23(82.14)$ & 0.776 \\
\hline Female & 19 & $14(13.46)$ & $5(17.86)$ & \\
\hline \multicolumn{5}{|l|}{ Age(years) } \\
\hline Mean & 58.8 & 58.8 & 58.6 & \\
\hline Range & $37-80$ & $37-80$ & $45-74$ & \\
\hline$\leq 50, \mathbf{n}(\%)$ & 18 & $12(11.55)$ & $6(21.43)$ & 0.297 \\
\hline$>50, \mathrm{n}(\%)$ & 114 & $92(88.46)$ & $22(78.57)$ & \\
\hline \multicolumn{5}{|l|}{ Smoking,n(\%) } \\
\hline Never & 25 & $16(15.38)$ & $9(32.14)$ & 0.123 \\
\hline$\leq 20, \mathrm{n}(\%)$ & 19 & $15(14.42)$ & $4(14.29)$ & \\
\hline$>20, \mathrm{n}(\%)$ & 88 & $73(70.20)$ & $15(53.57)$ & \\
\hline \multicolumn{5}{|l|}{ Alcohol use,n(\%) } \\
\hline Never & 66 & $45(43.27)$ & $21(75.00)$ & 0.007 \\
\hline$\leq 20, \mathbf{n}(\%)$ & 23 & $19(18.27)$ & $4(14.29)$ & \\
\hline$>20, \mathrm{n}(\%)$ & 43 & $40(38.46)$ & $3(10.71)$ & \\
\hline \multicolumn{5}{|l|}{$\mathrm{T}$} \\
\hline \multicolumn{5}{|l|}{ classification,n(\%) } \\
\hline T1-T2 & 114 & $88(84.62)$ & $26(92.86)$ & 0.413 \\
\hline T3-T4 & 18 & $16(15.38)$ & $2(7.140)$ & \\
\hline \multicolumn{5}{|l|}{ Node Status,n(\%) } \\
\hline No & 91 & $67(64.42)$ & $24(85.71)$ & 0.053 \\
\hline $\mathrm{N} 1-\mathrm{N} 2$ & 41 & $37(35.58)$ & $4(14.29)$ & \\
\hline \multicolumn{5}{|l|}{ TNM stage,n(\%) } \\
\hline Early(I and II) & 80 & $58(55.77)$ & $22(78.57)$ & 0.048 \\
\hline $\begin{array}{l}\text { Advanced(III and } \\
\text { IV) }\end{array}$ & 52 & $46(44.23)$ & $6(21.43)$ & \\
\hline \multicolumn{5}{|l|}{ Differentiation, $\mathrm{n}($} \\
\hline \multicolumn{5}{|l|}{$\%)$} \\
\hline Well & 60 & $43(41.35)$ & $17(46.43)$ & 0.153 \\
\hline Moderate & 60 & $50(48.08)$ & $10(35.71)$ & \\
\hline Poor & 12 & $11(10.57)$ & $1(3.570)$ & \\
\hline \multicolumn{5}{|l|}{ Tumor } \\
\hline \multicolumn{5}{|l|}{ location,n(\%) } \\
\hline Supraglottic & 70 & $58(55.77)$ & $12(42.86)$ & 0.254 \\
\hline Glottic & 44 & $31(29.81)$ & $13(46.43)$ & \\
\hline Subglottic & 18 & $15(14.42)$ & $3(10.71)$ & \\
\hline
\end{tabular}

Table 4. Presence of HPV DNA in LSCCs by location

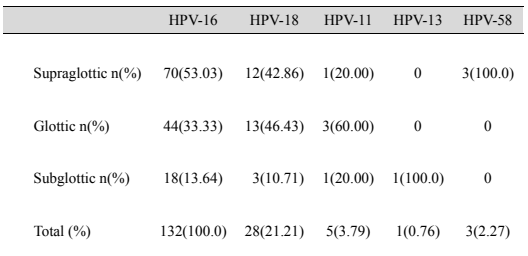

Fig. 2. Kaplan-Meier estimates of overall survival for LSCC patients. Overall survival of LSCCs according to p16 (A), HPV status (B) and single vs. multiple HPV infection (C). P-value calculated by log-rank test.

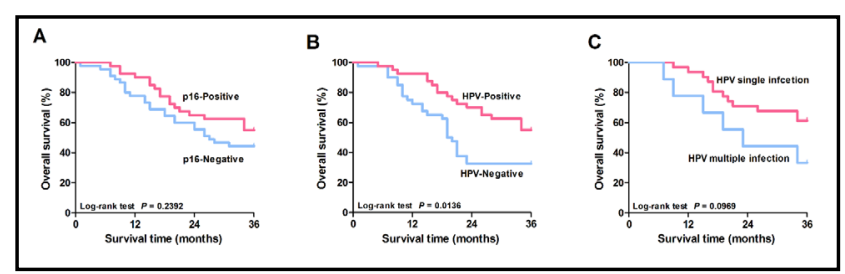




\section{Cellular Physiology Cell Physiol Biochem 2018;49:206-216 \begin{tabular}{l|l|l} 
and Biochemistry Published online: 22 August, 2018 & $\begin{array}{l}\text { @ } 2018 \text { The Author(s). Published by S. Karger AG, Basel } \\
\text { www.karger.com/cpb }\end{array}$ \\
\hline
\end{tabular}

expression did not correlate with overall survival (HR, 0.837; 95\% CI, 0.375-1.868; $P=0.664$ ). The results also showed that tumor location (glottic vs. others, HR, 0.477; 95\% CI, 0.240-0.949; $P=0.035$ ) correlated with overall survival. After adjusting the model for therapy, the results showed that HPV was a notable factor in the radiotherapy (RT+) group (HR, 0.064; 95\% CI, 0.007-0.558; $P=$ $0.013)$. However, HPV was less marked in the RT- group (HR, 0.538; 95\% CI, 0.2101.377; $P=0.196$ ).

\section{TCGA and GEO data analysis}

The LSCC cohort from TCGA and GEO datasets was also used to investigate the relationship between HPV/p16 and clinical outcome. The data showed that p16 expression was strongly associated with HPV infection (62.50\% in HPV+ tumors vs. $37.50 \%$ in HPV- tumors, $P<0.01$ ) (Table 6).

The demographic and clinical characteristics of patients with LSCC are presented in Table 7. All samples with comprehensive information $(n=74)$ were included in our analysis. The average age was 62 years (range 41-83). The majority of patients were male and exhibited advanced disease (stage III or IV) at diagnosis with a history of smoking. We analyzed the patients based on HPV status. HPV+ patients tended to be slightly younger than HPV- patients $(11.11 \%$ vs. $9.230 \%$, respectively, $P$ $=0.669)$. HPV + patients tended to present more frequently with an N1-N2 classification compared with HPV- patients $(66.67 \%$ vs. $47.69 \%$, respectively, $P=0.447)$. There was no significant correlation of HPV status with age, smoking, or alcohol use.

The overall survival of LSCC patients stratified by HPV status was assessed using Kaplan-Meier analysis. HPV+ patients exhibiting better overall survival than HPV- patients (Fig. 3A), but the difference was not statistically significant $(P=0.7515)$.

In order to confirm the reliability of our finding on HPV status and prognosis, the clinical and survival data of patients with HNSCC from the GEO dataset were analyzed. Kaplan-Meier analysis showed that HPV+ patients exhibited better overall survival than HPV- patients $(P=0.0091)$ (Fig. 3B). In addition, HPV RNA+ patients showed a significantly better outcome than HPV RNA- patients $(P=0.0173)$ (Fig. 3C).

\section{Discussion}

In this study, we investigated whether HPV status correlated with the survival of LSCC patients. The presence of HPV DNA in tumor tissue samples was determined by PCR and ISH. The combination of these two approaches detects HPV infection more reliably than either method alone, with $97 \%$ sensitivity
Table 6. The status of HPV and p16 expression in LSCCs from TCGA. $P$-values were calculated with chi-square test

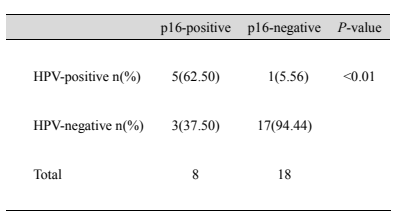

Table 7. Demographic and clinical characteristics in LSCCs from TCGA and GEO datasets. $P$-values were calculated with chi-square test

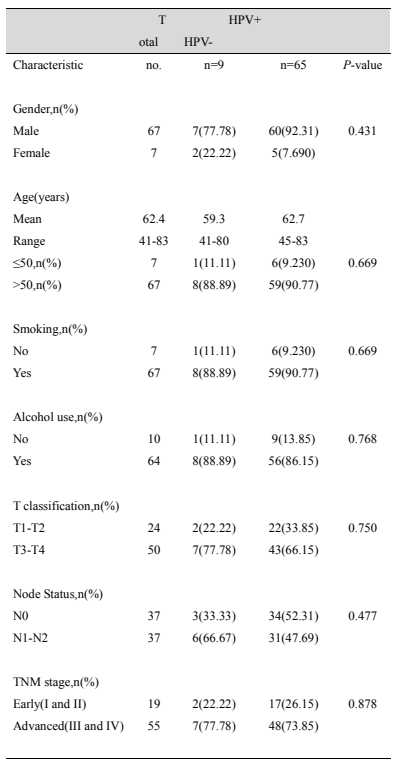



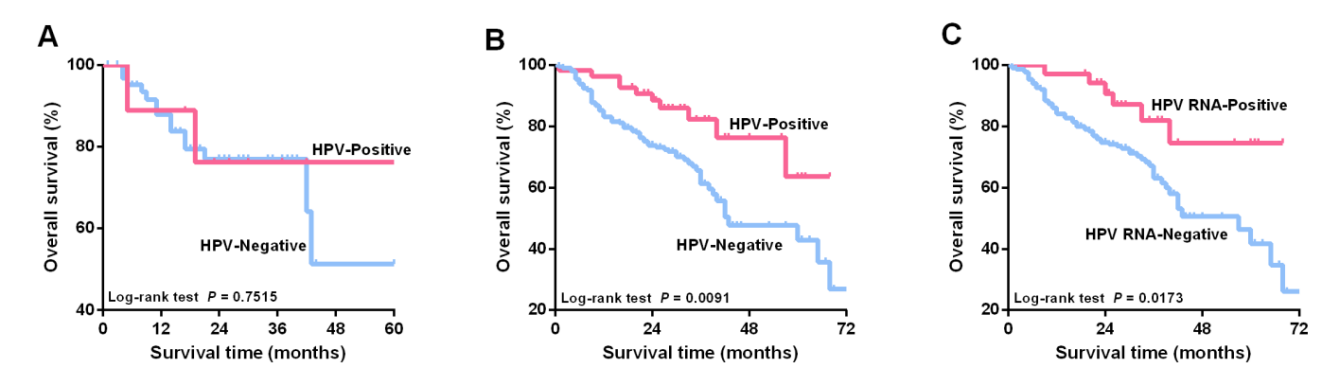

Fig. 3. Kaplan-Meier estimates of overall survival for LSCCs from TCGA and GEO. Overall survival of LSCCs according to HPV status from TCGA and GEO datasets(A). Overall survival of HNSCCs according to HPV DNA and RNA status(B, C). P-value calculated by log-rank test.

and 94\% specificity [20]. HPV infection status and p16 expression were evaluated in 211 LSCC patients from northeast China; $62.6 \%$ of patients were HPV+, a higher incidence than reported in a previous study that detected HPV DNA in 51\% of LSCC patients in northeast China [21]. A recent comprehensive review showed that the prevalence of HPV in LSCC varied from $0 \%$ to $85 \%$ [22]. This variability may reflect the use of different detection techniques, different detection criteria, and different sampling procedures (biopsy, formalin fixation, or tissue freezing) as well as racial differences and regional variations [23-25]. D'Souza et al. found that the prevalence of HPV was different among all racial groups [26].

Previous studies showed that HPV infection is strongly correlated with p16 overexpression in LSCC [4]. We found that the majority of our LSCC HPV+ samples were p16+, and this was also true of the LSCC cohort from TCGA and GEO datasets. The molecular mechanisms underlying HPV-associated tumorigenesis, namely, abrogation of p53 and pRB by the E6 and E7 oncogenes, respectively, are well-known, as is the associated overexpression of p16. In our study, 3.8\% of p16+ patients were HPV-, which could be attributed to other genetic perturbations. Rietbergen et al. found that alterations to host cell genes could lead to p16 overexpression in HPV- patients with oropharyngeal carcinoma [27].

We found a significantly higher proportion of p16 overexpression among patients with longer ( $>20$ years) smoking histories. This result differs from other reports showing little tobacco exposure among p16+ HNSCC patients [28]. However, more recent studies demonstrated that tobacco increases the risk of HPV infection as well as p16 overexpression. It is known that high levels of nicotine can greatly affect immunity. Nicotine can impair antigen-mediated signal transduction and induce T cell anergy. The exposure duration and concentration of nicotine may account for its immunosuppressive and anti-inflammatory properties [29]. Thus, patients with longer tobacco exposure may be more susceptible to HPV infection.

We observed that HPV+ tumors tended to present as moderately differentiated lesions, while HPV- tumors were more differentiated, which is consistent with previous studies [4]. We also observed an association between HPV infection and tumor location. The frequency of HPV infection was higher in glottic tumors than in tumors in other locations. Zetels et al. observed that glottic lesions were often exophytic and not deeply invasive, similar to OPSCC. Glottic cancer is morphologically similar to benign recurrent respiratory papillomatosis [30]. The route of HPV infection may account for the observed histological similarities with OPSCC.

As patients with p16+ or HPV+ OPSCC reportedly have a better prognosis, we investigated whether this was also true in LSCC patients. We found that HPV+ patients had significantly better overall survival than HPV- patients, but no significant relationship was observed between p16 expression and survival. Whether p16 overexpression can be used to predict prognosis in LSCC remains controversial. Recent reports suggest that p16 is not a reliable predictor of prognosis in LSCC. Young et al. analyzed the clinical outcome of patients 


\section{Cellular Physiology Cell Physiol Biochem 2018;49:206-216 \begin{tabular}{ll|l} 
and Biochemistry Published online: 22 August, 2018 & $\begin{array}{l}\text { (c) } 2018 \text { The Author(s). Published by S. Karger AG, Basel } \\
\text { www.karger.com/cpb }\end{array}$ \\
\hline
\end{tabular}

with LSCC stratified on the basis of p16 expression and concluded that there was no survival advantage among p16+ patients [31]. Consistent with most of the previous findings, our study suggests that HPV infection status is a more reliable surrogate marker than p16 for predicting survival in patients with LSCC.

On the basis of the above results, we further investigated HPV infection status and its relation to clinical outcome. We found that the main HPV genotype in LSCC was HPV-16. Syrjänen et al. reported that HPV-16 was present in 89\% of patients with HPV+ HNSCC [32]. LSCC patients with an HPV-16 single infection most frequently present at an early stage (stage I-II) with advanced node status (N1-N2). Similar results were observed for patients with HNSCC and OPSCC [33, 34]. In our study, 28 cases (21.2\%) had multiple HPV infections. Patients with a single HPV infection had better survival than patients with multiple HPV infections. Little is known, however, about multiple HPV infections.

Multivariate analysis of overall survival in patients with LSCC showed that HPV was a notable factor in the RT+ group; however, HPV was less marked in the RT-group. This result was consistent with many studies demonstrating that patients with HPV+ head and neck cancer (HNC) had markedly improved survival outcomes when treated with radiation. Kimple et al. reported that HPV+ HNC cell lines were more sensitive to radiation than HPVHNC cells in vitro and in vivo. In addition, it was suggested that increased TP53-induced apoptosis following radiation exposure plays a key role in the increased radiosensitivity of HPV+ HNC [35]. Rieckman et al. demonstrated that impaired DNA repair capacity was responsible for the increased response to radiotherapy of HPV+ cells [36]. Further studies will be necessary to investigate the role of HPV in enhancing radiosensitivity. Whether radiation alone is sufficient to treat HPV+ LSCC is unknown. Further research is necessary to take advantage of this phenomenon to develop more appropriate therapeutic strategies for patients with LSCC.

We used GEO data to investigate whether the better prognosis of HPV+ patients was related to the presence of HPV RNA. We found that HPV RNA+ patients showed a significantly better outcome than HPV RNA- patients. HPV RNA+ patients had a slightly higher survival rate than HPV DNA+ patients. However, this analysis was limited by the number of available patients. Differentially expressed genes in HPV RNA+ and HPV RNA- HNSCC were mainly enriched in the immune response biological process (Fig. 4). This was consist with many studies showing that HPV RNA+ was the main factor for prognosis [37].

There are several limitations of our study. Neither the physical status of HPV DNA (integrated vs. episomal) nor the transcriptional activity of E6/E7 oncogenes was examined. Vojtechova et al. reported that both integrated and episomal HPV was associated with a significantly better prognosis compared with HPV- cases of OPSCC [38]. HPV DNA alone is not sufficient to claim causality in LSCC. Indeed, determining HPV causality in LSCC has become a tremendous challenge for researchers. HPV RNA expression is regarded as a reliable biomarker to identify LSCC with active HPV-16 involvement. PCR-based assays are highly sensitive, and an HPV DNA+ finding can be caused not only because of HPVdriven carcinogenesis but also because a non-transforming infection may have been identified in the tumor or neighboring tissue. Some researchers choose $\mathrm{p} 16$ or pRB as a surrogate marker to identify tumors with active HPV expression; however, p16 IHC has insufficient sensitivity and specificity. Holzinger et al. found that $22 \%$ of HPV RNA+ OPSCC samples were p16-. In addition, among 14-21\% of HPVsamples, the expression levels of p16 were upregulated with no evidence of an HPV-16 transforming infection [39]. In our study, we

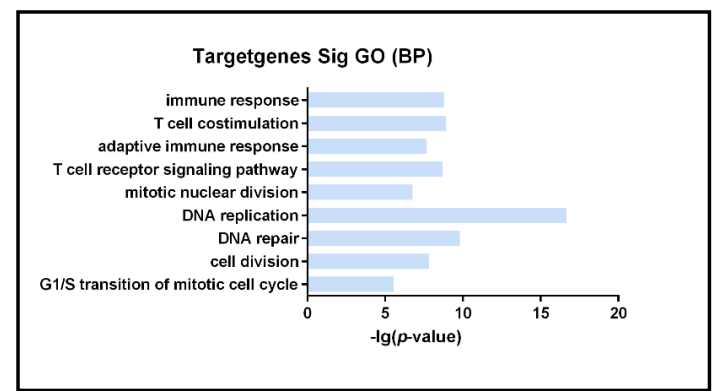

Fig. 4. Go analysis of differentially expressed genes between HPV RNA+ and HPV RNA- HNSCCs. GO annotation of the top 10 functional GO terms for biological process. 


\section{Cellular Physiology Cell Physiol Biochem 2018;49:206-216 \begin{tabular}{ll|l} 
DOI: 10.1159/000492858 & $\begin{array}{l}\text { O 2018 The Author(s). Published by S. Karger AG, Basel } \\
\text { www.karger.com/cpb }\end{array}$ \\
\hline
\end{tabular}

were unable to detect E6/E7 mRNA expression in LSCC samples, likely because the formalinfixed and paraffin-embedded samples were not suitable for detection. Bishop et al. reported that transcriptionally active HPV could be detected in formalin-fixed and paraffin-embedded HNSCC samples by using RNAscope, which is more sensitive and specific than RNA ISH, IHC, and PCR [40]. Thus, we intend to analyze E6/E7 mRNA expression to distinguish HPVdriven LSCC in our next study. The analysis presented here may be affected by the number of cases, so it is necessary for us to make full use of global datasets or existing literature to seek additional samples and cooperation for further studies.

In conclusion, we found that $63.2 \%$ of LSCC patients were positive for HPV infection in Harbin, northeast China. HPV status was an independent prognostic factor for survival in patients with LSCC. Although p16 overexpression was largely correlated with HPV infection, p16 was subject to the influence of additional factors. Thus, HPV was a more reliable surrogate marker than p16 for survival in patients with LSCC. Further studies are needed to investigate the role of HPV in LSCC and to develop optimal treatment approaches for patients with LSCC.

\section{Abbreviations}

HPV (human papillomavirus); HNCs (head and neck cancers); LSCCs (laryngeal squamous cell carcinomas); OPSCCs (oropharyngeal squamous cell carcinomas); RB1 (retinoblastoma 1); HNSCC (head and neck squamous cell carcinoma); TCGA (the cancer genome atlas).

\section{Acknowledgements}

This study was supported by National Natural Science Foundation of China (NO. 81672670 and 81600539), Youth Elite Training Foundation of Harbin Medical University Cancer Hospital (NO. JY2016-06), Harbin Special Fund Project for Science and Technology Innovation (NO. 2016RAQXJ203), Graduate Innovation Research Project of Harbin Medical University (NO. YJSCX2017-8HYD) and Heilongjiang Provincial Science and Technology Innovation Team in Higher Education Institute for Infection and Immunity.

\section{Disclosure Statement}

The authors declare that they have no conflicts of interest.

\section{References}

1 Kamangar F, Dores GM, Anderson WF: Patterns of cancer incidence, mortality, and prevalence across five continents: defining priorities to reduce cancer disparities in different geographic regions of the world. J Clin Oncol 2006;24:2137-2150.

-2 Leemans CR, Snijders PJF, Brakenhoff RH: The molecular landscape of head and neck cancer. Nat Rev Cancer 2018; DOI:10.1038/nrc.2018.11.

-3 Leemans CR, Braakhuis BJ, Brakenhoff RH: The molecular biology of head and neck cancer. Nature Reviews Cancer 2011;11:9-22.

4 Marur S, D'Souza G, Westra WH, Forastiere AA: HPV-associated head and neck cancer: a virus-related cancer epidemic. Lancet Oncol 2010;11:781-789.

5 Chaturvedi AK: Epidemiology and clinical aspects of HPV in head and neck cancers. Head Neck Pathol 2012;6:S16-24.

6 zur Hausen H: Papillomaviruses and cancer: from basic studies to clinical application. Nat Rev Cancer 2002;2:342-350. 


\section{Cellular Physiology Cell Physiol Biochem 2018;49:206-216 \begin{tabular}{ll|l} 
and Biochemistry Published online: 22 August, 2018 & $\begin{array}{l}\text { (c) } 2018 \text { The Author(s). Published by S. Karger AG, Basel } \\
\text { www.karger.com/cpb }\end{array}$ \\
\hline
\end{tabular}

7 Reimers N, Kasper HU, Weissenborn SJ, Stutzer H, Preuss SF, Hoffmann TK, Speel EJ, Dienes HP, Pfister HJ, Guntinas-Lichius O, Klussmann JP: Combined analysis of HPV-DNA, p16 and EGFR expression to predict prognosis in oropharyngeal cancer. Int J Cancer 2007;120:1731-1738.

8 Zhen S, Li X: Oncogenic Human Papillomavirus: Application of CRISPR/Cas9 Therapeutic Strategies for Cervical Cancer. Cell Physiol Biochem 2017;44:2455-2466.

-9 Langendijk JA, Psyrri A: The prognostic significance of p16 overexpression in oropharyngeal squamous cell carcinoma: Implications for treatment strategies and future clinical studies. Ann Oncol 2010;21:19311934.

10 Torre LA, Bray F, Siegel RL, Ferlay J, Lortet-Tieulent J, Jemal A: Global cancer statistics, 2012 CA Cancer J Clin 2015;65:87-108.

-11 Ferlay J, Shin HR, Bray F, Forman D, Mathers C, Parkin DM: Estimates of worldwide burden of cancer in 2008: GLOBOCAN 2008. Int J Cancer 2010;127:2893-2917.

12 Pytynia KB, Dahlstrom KR, Sturgis EM: Epidemiology of HPV-associated oropharyngeal cancer. Oral Oncol 2014;50:380-386.

13 Chaturvedi AK, Engels EA, Pfeiffer RM, Hernandez BY, Xiao W, Kim E, Jiang B, Goodman MT, Sibug-Saber M, Cozen W, Liu L, Lynch CF, Wentzensen N, Jordan RC, Altekruse S, Anderson WF, Rosenberg PS, Gillison ML: Human papillomavirus and rising oropharyngeal cancer incidence in the United States. J Clin Oncol 2011;29:4294-4301.

14 Kreimer AR, Clifford GM, Boyle P, Franceschi S: Human papillomavirus types in head and neck squamous cell carcinomas worldwide: a systematic review. Cancer Epidemiol Biomarkers Prev 2005;14:467-475.

-15 Xu Y, Liu S, Yi H, Wang J, Dong P, Li X, Yin S: Human papillomavirus infection in 674 Chinese patients with laryngeal squamous cell carcinoma. PLoS One 2014;9:e115914.

16 Lewis JS, Jr., Thorstad WL, Chernock RD, Haughey BH, Yip JH, Zhang Q, El-Mofty SK: p16 positive oropharyngeal squamous cell carcinoma:an entity with a favorable prognosis regardless of tumor HPV status. Am J Surg Pathol 2010;34:1088-1096.

17 Liederbach E, Kyrillos A, Wang CH, Liu JC, Sturgis EM, Bhayani MK: The national landscape of human papillomavirus-associated oropharynx squamous cell carcinoma. Int J Cancer 2016; DOI:10.1002/ ijc.30442.

-18 Gronhoj Larsen C, Jensen DH, Carlander AF, Kiss K, Andersen L, Olsen CH, Andersen E, Garnaes E, Cilius F, Specht L, von Buchwald C: Novel nomograms for survival and progression in HPV+ and HPVoropharyngeal cancer: a population-based study of 1, 542 consecutive patients. Oncotarget 2016; DOI:10.18632/oncotarget.12335.

19 Saqi A, Pasha TL, McGrath CM, Yu GH, Zhang P, Gupta P: Overexpression of p16INK4A in liquid-based specimens (SurePath) as marker of cervical dysplasia and neoplasia. Diagn Cytopathol 2002;27:365-370.

20 Schache AG, Liloglou T, Risk JM, Filia A, Jones TM, Sheard J, Woolgar JA, Helliwell TR, Triantafyllou A, Robinson M, Sloan P, Harvey-Woodworth C, Sisson D, Shaw RJ: Evaluation of human papilloma virus diagnostic testing in oropharyngeal squamous cell carcinoma: sensitivity, specificity, and prognostic discrimination. Clin Cancer Res 2011;17:6262-6271.

-21 Ma XL, Ueno K, Pan ZM, Hi SZ, Ohyama M, Eizuru Y: Human papillomavirus DNA sequences and p53 overexpression in laryngeal squamous cell carcinomas in Northeast China. J Med Virol 1998;54:186-191.

-22 Gama RR, Carvalho AL, Longatto Filho A, Scorsato AP, Lopez RV, Rautava J, Syrjanen S, Syrjanen K: Detection of human papillomavirus in laryngeal squamous cell carcinoma: Systematic review and meta-analysis. Laryngoscope 2016;126:885-893.

23 Liu H, Li J, Diao M, Cai Z, Yang J, Zeng Y: Statistical analysis of human papillomavirus in a subset of upper aerodigestive tract tumors. J Med Virol 2013;85:1775-1785.

-24 Smith EM, Rubenstein LM, Ritchie JM, Lee JH, Haugen TH, Hamsikova E, Turek LP: Does pretreatment seropositivity to human papillomavirus have prognostic significance for head and neck cancers? Cancer Epidemiol Biomarkers Prev 2008;17:2087-2096.

25 Koskinen WJ, Chen RW, Leivo I, Makitie A, Back L, Kontio R, Suuronen R, Lindqvist C, Auvinen E, Molijn A, Quint WG, Vaheri A, Aaltonen LM: Prevalence and physical status of human papillomavirus in squamous cell carcinomas of the head and neck. Int J Cancer 2003;107:401-406. 


\section{Cellular Physiology Cell Physiol Biochem 2018;49:206-216

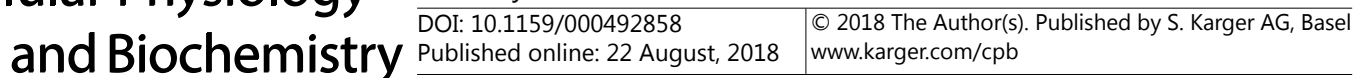 \\ Tong et al.: Prognostic Significance of HPC in Laryngeal Cancer}

26 D’Souza G, Westra WH, Wang SJ, van Zante A, Wentz A, Kluz N, Rettig E, Ryan WR, Ha PK, Kang H, Bishop J, Quon H, Kiess AP, Richmon JD, Eisele DW, Fakhry C: Differences in the Prevalence of Human Papillomavirus (HPV) in Head and Neck Squamous Cell Cancers by Sex, Race, Anatomic Tumor Site, and HPV Detection Method. JAMA Oncol 2016; DOI:10.1001/jamaoncol.2016.3067.

-27 Rietbergen MM, Snijders PJ, Beekzada D, Braakhuis BJ, Brink A, Heideman DA, Hesselink AT, Witte BI, Bloemena E, Baatenburg-De Jong RJ, Leemans CR, Brakenhoff RH: Molecular characterization of p16immunopositive but HPV DNA-negative oropharyngeal carcinomas. Int J Cancer 2014;134:2366-2372.

28 Maxwell JH, Grandis JR, Ferris RL: HPV-Associated Head and Neck Cancer: Unique Features of Epidemiology and Clinical Management. Annu Rev Med 2016;67:91-101.

29 Mehta H, Nazzal K, Sadikot RT: Cigarette smoking and innate immunity. Inflammation Research 2008;57:497-503.

30 Zeitels SM: Glottic Cancer: A Metamorphosing Disease. Ann Otol Rhinol Laryngol 2016;125:452-456.

-31 Young RJ, Urban D, Angel C, Corry J, Lyons B, Vallance N, Kleid S, Iseli TA, Solomon B, Rischin D: Frequency and prognostic significance of p16INK4A protein overexpression and transcriptionally active human papillomavirus infection in laryngeal squamous cell carcinoma. Br J Cancer 2015;112:1098-1104.

-32 Syrjanen S: The role of human papillomavirus infection in head and neck cancers. Ann Oncol 2010;21:vii243-245.

-33 Zaravinos A: An updated overview of HPV-associated head and neck carcinomas. Oncotarget 2014;5:39563969.

-34 Stein AP, Saha S, Yu M, Kimple RJ, Lambert PF: Prevalence of human papillomavirus in oropharyngeal squamous cell carcinoma in the United States across time. Chem Res Toxicol 2014;27:462-469.

-35 Kimple RJ, Smith MA, Blitzer GC, Torres AD, Martin JA, Yang RZ, Peet CR, Lorenz LD, Nickel KP, Klingelhutz AJ, Lambert PF, Harari PM: Enhanced radiation sensitivity in HPV-positive head and neck cancer. Cancer Res 2013;73:4791-4800.

-36 Rieckmann T, Tribius S, Grob TJ, Meyer F, Busch CJ, Petersen C, Dikomey E, Kriegs M: HNSCC cell lines positive for HPV and p16 possess higher cellular radiosensitivity due to an impaired DSB repair capacity. Radiother Oncol 2013;107:242-246.

37 Garnaes E, Frederiksen K, Kiss K, Andersen L, Therkildsen MH, Franzmann MB, Specht L, Andersen E, Norrild B, Kjaer SK, von Buchwald C: Double positivity for HPV DNA/p16 in tonsillar and base of tongue cancer improves prognostication: Insights from a large population-based study. Int J Cancer 2016;139:2598-2605.

38 Vojtechova Z, Sabol I, Salakova M, Turek L, Grega M, Smahelova J, Vencalek O, Lukesova E, Klozar J, Tachezy R: Analysis of the integration of human papillomaviruses in head and neck tumours in relation to patients' prognosis. Int J Cancer 2016;138:386-395.

-39 Holzinger D, Flechtenmacher C, Henfling N, Kaden I, Grabe N, Lahrmann B, Schmitt M, Hess J, Pawlita M, Bosch FX: Identification of oropharyngeal squamous cell carcinomas with active HPV16 involvement by immunohistochemical analysis of the retinoblastoma protein pathway. Int J Cancer 2013;133:1389-1399.

-40 Bishop JA, Ma XJ, Wang H, Luo Y, Illei PB, Begum S, Taube JM, Koch WM, Westra WH: Detection of transcriptionally active high-risk HPV in patients with head and neck squamous cell carcinoma as visualized by a novel E6/E7 mRNA in situ hybridization method. Am J Surg Pathol 2012;36:1874-1882. 